\title{
Selective blockade of retrograde fast pathway by intravenous disopyramide in paroxysmal supraventricular tachycardia mediated by dual atrioventricular nodal pathways
}

\author{
KAMAL K SETHI, S JAISHANKAR, M KHALILULLAH, M P GUPTA \\ From the Department of Cardiology, GB Pant Hospital, New Delhi, India
}

SUMMARY Electrophysiological effects of 2 to $2.5 \mathrm{mg} / \mathrm{kg}$ iv disopyramide were studied in 10 patientso with dual nodal pathways who used a slow pathway for anterograde and a fast pathway for retro-grade conduction during paroxysmal supraventricular tachycardia (mean cycle length $308.5 \pm 37 \mathrm{~ms} ; \Leftarrow$ range $260-370 \mathrm{~ms}$ ). Disopyramide terminated the tachycardia in six cases by production of ven- $\overline{\mathrm{D}}$ triculoatrial block in five and by sinus overdrive in one. In the remaining four patients cycle length $\overrightarrow{0}$ of the paroxysmal supraventricular tachycardia increased significantly from $270 \pm 8 \mathrm{~ms}$ to $377 \cdot 5 \pm 28^{\circ 0} \mathrm{c}$ ms. In all 10 patients disopyramide depressed retrograde fast pathway conduction manifest by an increase in mean ventricular paced cycle length producing ventriculoatrial block from $\leqslant 296 \cdot 5 \pm 25 \$$ $\mathrm{ms}$ to $358 \pm 60 \mathrm{~ms}$, and increase in retrograde fast pathway effective refractory period from $\leqslant 246 \pm 34 \div$ ms to $325 \pm 36 \mathrm{~ms}$; the drug abolished ventriculoatrial conduction in two cases.

Anterograde slow pathway and fast pathway conduction properties were unchanged after diso- $\frac{0}{2}$ pyramide (atrial paced cycle length producing AH block $292 \pm 30$ to $306 \cdot 5 \pm 30 \mathrm{~ms}$; effective refrac- $\overrightarrow{\overrightarrow{0}}$ tory period of anterograde fast pathway $\leqslant 274 \pm 56$ to $284 \pm 44 \mathrm{~ms}$, before and after the drug, respectively) suggesting that anterograde conduction was not crucial either for sustainment or for failure to initiate paroxysmal supraventricular tachycardia after the drug.

Paroxysmal supraventricular tachycardia could not be reinduced in six cases after disopyramide. In the other four the ventricular paced cycle lengths producing ventriculoatrial block $(318 \pm 41 \mathrm{~ms}) \stackrel{\mathrm{m}}{\mathrm{N}}$ and effective refractory period of retrograde fast pathway $(320 \pm 28 \mathrm{~ms})$ were shorter than the cycle length of reinduced paroxysmal supraventricular tachycardia $(367 \cdot 5 \pm 35 \mathrm{~ms})$ allowing perpetuation of the tachycardia.

We conclude that disopyramide breaks atrioventricular nodal re-entrant tachycardia by specific blockade of the retrograde fast pathway though the effect on anterograde atrioventricular nodaP conduction is variable.

Electrophysiological studies have shown that longitudinal dissociation of the antrioventricular node into dual pathways constitutes the most common mechanism of re-entry in the mediation of paroxysmal supraventricular tachycardia. ${ }^{2}$ Usually the tachycardia uses the slow pathway for anterograde conduction and the fast pathway for the return impulse; and the three most commonly recommended drugs, that is verapamil, digitalis, and propranolol, inhibit the arrhythmia by depression of conduction through the

Accepted for publication 10 February 1983 anterograde slow pathway..$^{3-5}$ Some studies have also $N$ reported the effects of procainamide ${ }^{6}$ and quinidine ${ }^{7}{ }^{7} \mathrm{C}$ on laboratory induction of paroxysmal supraventricu $=$ lar tachycardia.

Disopyramide phosphate, a synthetic compound with antiarrhythmic actions similar to those of $\stackrel{\text { ? }}{-}$ quinidine, was introduced by Mokler and Vant Arman $^{9}$ in 1962. Because of its demonstrably variable? effects on the atrioventricular nodal conduction and refractory periods it was not construed to be effective $e_{\stackrel{\mathbb{D}}{\alpha}}$ in paroxysmal supraventricular tachycardia mediatedo by dissociation of the atrioventricular node into dual 
pathways. ${ }^{1011}$ On the other hand, in patients with paroxysmal supraventricular tachycardia associated with Wolff-Parkinson-White syndrome, disopyramide inhibits both anterograde and retrograde conduction through the bypass $\operatorname{tract}^{1012}$ and has been recommended for use in paroxysmal supraventricular tachycardia using atrioventricular node bypass tract. A few studies conducted in a small cohort of patients without overt pre-excitation have shown that intravenous disopyramide terminates 33 to $68 \%$ of acute attacks of paroxysmal supraventricular tachycardia. ${ }^{13-16}$ No intracardiac electrophysiological studies to delineate the mechanism of paroxysmal supraventricular tachycardia or its mode of termination were, however, performed in any of these investigations. It is well recognised that concealed atrioventricular accessory pathways, functionally silent during sinus rhythm and therefore clinically unsuspected, participate in 15 to $30 \%$ cases of re-entrant paroxysmal supraventricular tachycardia ${ }^{17}$; hence it becomes obligatory to rule out participation of this circuit in evaluating the effect of drugs on atrioventricular nodal re-entrant paroxysmal supraventricular tachycardia. The efficacy of intravenous disopyramide in terminating episodes of paroxysmal supraventricular tachycardia in a select group of patients with dual atrioventricular nodal pathway mediation has thus far not been adequately investigated, and formed the aim of the present study.

\section{Subjects and methods}

Ten patients, four men and six women, aged 25 to 56 years (mean 42.8 years) comprised the study material selected on the following criteria: (1) a history of electrocardiographic documented recurrent paroxysmal supraventricular tachycardia, (2) absence of preexcitation during sinus rhythm in all available electrocardiograms, (3) electrophysiological documentation of longitudinal dissociation of the atrioventricular node during paroxysmal supraventricular tachycardia, and (4) exclusion of a retrogradely active concealed bypass tract during paroxysmal supraventricular tachycardia by intracardiac catheter techniques.

Electrophysiological studies were performed in the post-absorptive non-sedated state a week after discontinuation of all cardioactive medications. Informed written consent was obtained from all. One patient had angina of effort; others were free of organic heart disease.

Six $6 \mathrm{~F}$ bipolar catheters were introduced transvenously and positioned at high, mid, and low right atrium, coronary sinus, tricuspid valve (for His bundle electrogram), and right ventricular apex. The mid-right atrial and right ventricular electrodes were used for pacing and programmed stimulation. The electrograms from the high and low right atrium, tricuspid valve, and coronary sinus were recorded (frequency range 30 to $500 \mathrm{~Hz}$ ) together with multiple scalar leads (combinations of lead I, II, III, aVF, or V1) on VR-12 photographic recorder (Electronics for Medicine) or on Mingograf 8 channel ink jet recorder (Siemens-Elema) at paper speeds of 100 and 250 $\mathrm{mm} / \mathrm{s}$. Intracardiac stimulation was performed at approximately twice the diastolic threshold by a battery powered stimulator (Digitimer arrhythmia investigating system, Neurolog-4279) producing square wave pulses of $2 \mathrm{~ms}$ duration.

The study consisted of evaluation of anterograde and retrograde conduction properties, refractory periods of the slow and fast pathways, and the mechanism of paroxysmal supraventricular tachycardia, pursued in the following sequence: (a) incremental atrial pacing to a paced cycle length producing atrioventricular block; (b) programmed atrial extrastimulus testing at decreasing coupling intervals using single $\left(A_{1} A_{2}\right)$ extrastimuli during sinus rhythm and during one or more atrial paced cycle lengths. Double extrastimuli $\left(A_{1} A_{2} A_{3}\right)$ were given when single stimuli failed to induce paroxysmal supraventricular tachycardia; (c) incremental ventricular pacing to a paced cycle length producing ventriculoatrial block; (d) programmed ventricular extrastimulation at decremental coupling intervals at a driven ventricular cycle length just shorter than sinus cycle length; (e) induction of paroxysmal supraventricular tachycardia by rapid atrial pacing, atrial or ventricular extrastimulation, and delineation of the limbs of the reentrant circuit by analysis of the mode of initiation of paroxysmal supraventricular tachycardia, anterograde and retrograde conduction times, and sequence of retrograde atrial activation (from endocardial map recorded from multiple atrial sites); and (f) ventricular programmed extrastimulation during induced paroxysmal supraventricular tachycardia to rule out concealed septal bypass tract participation.

After the verification of dual atrioventricular nodal pathway participation during paroxysmal supraventricular tachycardia, $2 \mathrm{mg} / \mathrm{kg}$ of disopyramide phosphate was injected intravenously over a period of three minutes. Cuff blood pressure was closely monitored. Intracardiac and surface electrograms were continuously recorded at paper speed of $50 \mathrm{~mm} / \mathrm{s}$ from the beginning of injection in order to study the mode of termination of the tachycardia. If the tachycardia failed to break within 10 minutes after initiation of injection, and if no side effects were encountered, an additional dose of $0.5 \mathrm{mg} / \mathrm{kg}$ was administered intravenously over one minute (four patients). If the paroxysmal supraventricular tachycardia was not abolished in the following five minutes, it was terminated electrically by atrial extra- 
stimulus or atrial overdrive pacing.

After conversion to sinus rhythm by either mode, the cycle length, $\mathrm{AH}$, and $\mathrm{HV}$ intervals were recorded at paper speed of $100 \mathrm{~mm} / \mathrm{s}$. Atrial and ventricular pacing and extrastimulation studies were then conducted in the sequence described earlier and an attempt was made to reinduce paroxysmal supraventricular tachycardia. The post-drug studies were completed within 30 minutes of termination of the arrhythmia.

\section{ELECTROPHYSIOLOGICAL DEFINITIONS}

$\mathrm{RA}_{1}, \mathrm{CS}_{1}, \mathrm{Al}, \mathrm{H}_{1}$, and $\mathrm{V}_{1}$ are high right atrial, left atrial (recorded from coronary sinus), low septal right atrial, His bundle, and ventricular responses during sinus rhythm or driven atrial or ventricular stimuli $\left(S_{1}\right) . R A_{2}, C S_{2}, A_{2}, H_{2}$, and $V_{2}$ are respective responses to the extrastimulus $\left(\mathrm{S}_{2}\right)$. Conduction intervals and refractory periods were measured as defined by Wu et al.$^{18}$ Anterograde and retrograde block rates were defined as the longest paced cycle length (atrial and ventricular, respectively) which failed to conduct to the distal chamber. In an occasional case rapid pacing carried out to very high rates did not achieve block. In such cases the highest paced rate tested was considered to be the "block rate" for purposes of analysis. This occurred only during the control studies and not after the drug so that the magnitude of decrease in block rates attributed to disopyramide in these cases indicates the minimal values of decrement.

Diagnosis of atrioventricular nodal re-entrant paroxysmal supraventricular tachycardia was made using combinations of the following criteria.

(1) Induction of tachycardia related to achievement of a critical AH delay, with both incremental atrial pacing and atrial extrastimulation (10 patients). ${ }^{19-21}$

(2) Demonstration of discontinuous $A_{1} A_{2}$ to $H_{1} H_{2}$ curves, or two different $\mathrm{AH}$ intervals at identical pacing cycle length, suggestive of dual atrioventricular nodal pathways with induction of tachycardia related to anterograde block in the fast pathway (seven patients). 1821

Because it is possible to fulfil criteria (1) and (2) in patients with concealed extranodal bypass tracts, one or more of the following additional criteria were sought for the diagnosis of atrioventricular nodal re-entry.

(3) Normal retrograde atrial activation sequence during tachycardia, namely, low septal right atrium activated earlier than all other atrial sites (10 patients). ${ }^{22}$

(4) Demonstration of atrial activation simultaneous with onset of ventricular activation during tachycardia, suggesting that the ventricle is not an essential component of the re-entry circuit (10 patients). ${ }^{20}$

(5) Increase in ventriculoatrial interval with incremental ventricular pacing producing Mobitz type I block at a critical rate, suggesting retrograde atrioventricular nodal conduction ( 9 patients). ${ }^{18} 20$

(6) Demonstration of $\mathrm{His}$ bundle activation $\left(\mathrm{H}_{2}\right)$ preceding atrial activation $\left(A_{2}\right)$ with ventricular extrastimulus or pacing, suggesting retrograde atrioventricular nodal conduction (four patients). ${ }^{20}$

(7) Exclusion of concealed septal bypass tract by showing failure of programmed ventricular extrastimulation to pre-excite the atrium when delivered at the critical time when the His bundle was rendered refractory by anterograde depolarisation during the normal course of paroxysmal supraventricular tachycardia.

Patients with concealed bypass tract participation during the tachycardia ${ }^{2}$ were excluded from the study.

\section{Results}

The results are set out in the Table. The mean basal cycle length during sinus rhythm was $578 \pm 107 \mathrm{~ms}$ (range 440 to $740 \mathrm{~ms}$ ); the mean AH interval was $78.8 \pm 13 \mathrm{~ms}$ (range 60 to $90 \mathrm{~ms}$ ) and the mean HV time was $44 \pm 6 \mathrm{~ms}$ (range 35 to $50 \mathrm{~ms}$ ).

\section{INDUCTION OF PAROXYSMAL}

\section{SUPRAVENTRICULAR TACHYCARDIA}

Sustained paroxysmal supraventricular tachycardia could be induced in all 10 patients: by rapid atrial pacing in seven, by single atrial extrastimulus in three, by double atrial extrastimulus in two, and by rapid ventricular pacing in one case. Induction of paroxysmal supraventricular tachycardia by atrial stimulation was related to achievement of a critical AH prolongation consequent to anterograde block of the fast pathway and the resultant atrioventricular conduction via the slow pathway. Induction of paroxysmal supraventricular tachycardia by ventricular pacing was obtained without a ventriculoatrial delay, reflecting block in the retrograde slow pathway.

Cycle length of the tachycardia ranged between 260 and $370 \mathrm{~ms}$ (mean $308 \cdot 5 \pm 37 \mathrm{~ms}$ ). All patients showed anterograde conduction through the slow pathway and retrograde conduction through the fast pathway.

\section{TERMINATION OF PAROXYSMAL}

SUPRAVENTRICULAR TACHYCARDIA

Disopyramide could terminate paroxysmal supraventricular tachycardia in six cases. The break occurred immediately on completion of injection in three cases; and between one minute 30 seconds and four minutes 
ble Effect of disopyramide on paroxysmal supraventricular tachycardia

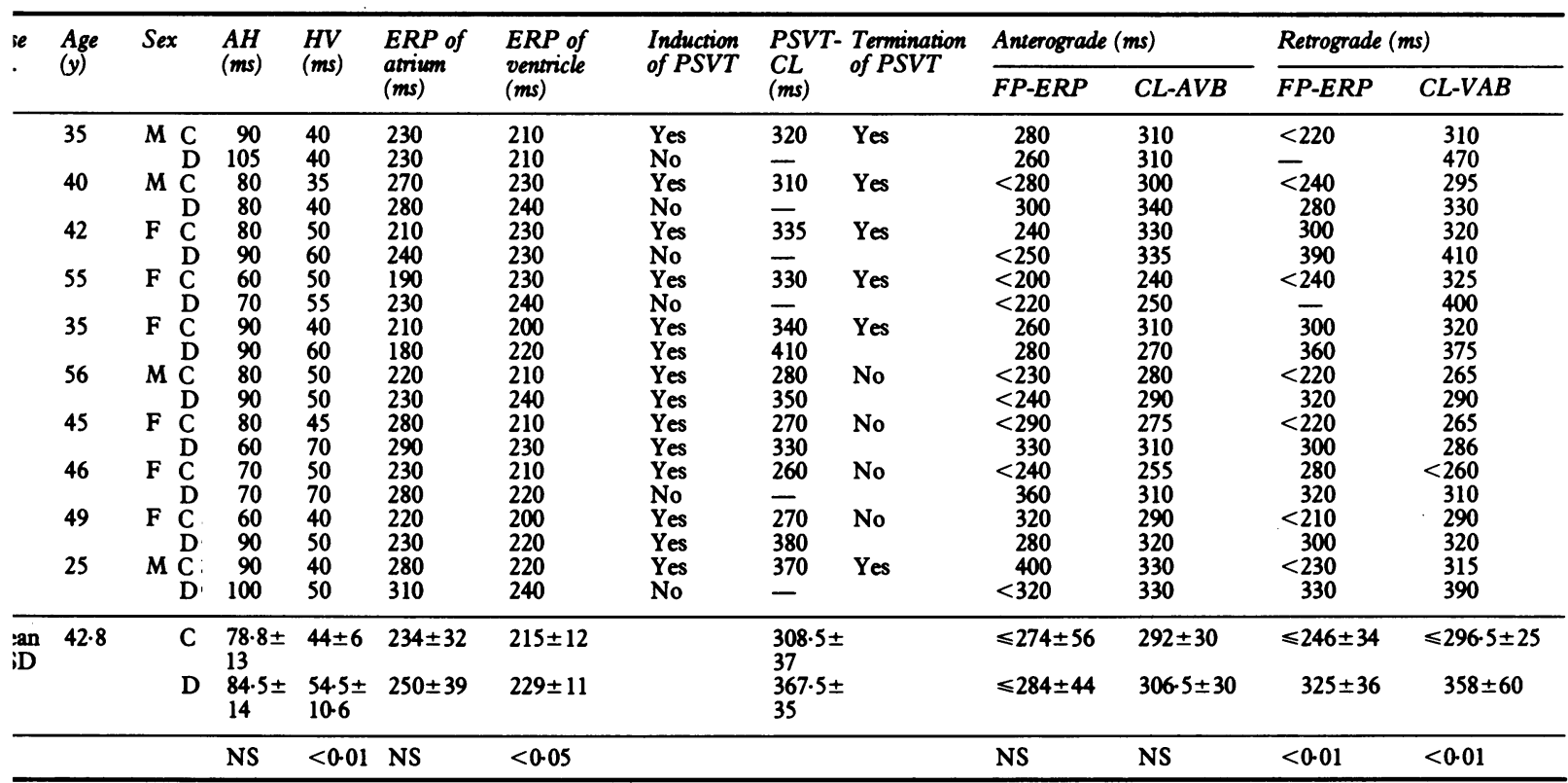

VT, paroxysmal supraventricular tachycardia; CL, cycle length; ERP, effective refractory period; FP-ERP, effective refractory period of the $t$ pathway; CL-AVB, longest atrial paced cycle length producing atrioventricular block; CL-VAB, longest ventricular paced cycle length ducing ventriculoatrial block; $C$, control; $D$, after intravenous disopyramide.

48 seconds (mean two minutes six seconds) after the injection in the other three. The break was achieved by ventriculoatrial block (retrograde fast pathway block) in five patients (cases 1, 2, 3, 4, and 10) (Fig. 1) and by sinus overdrive (described below) in the sixth case. Among the five cases showing venticuloatrial block, the cycle length of paroxysmal supraventricular tachycardia before termination remained unchanged in three (cases 1,4 , and 10) and increased from $315 \mathrm{~ms}$ (mean) to $390 \mathrm{~ms}$ (mean) in two (cases 2 and 3 ).

In the sixth patient (case 5) the arrhythmia was converted in a peculiar manner. The drug not only increased the cycle length of the tachycardia (from 340 to $380 \mathrm{~ms}$ ) but also accelerated the sinus cycle length to $370 \mathrm{~ms}$, producing an isorhythmic "sinusparoxysmal supraventricular tachycardia dissociation" as evidenced by activation of low septal right atrium by the retrograde impulse of the tachycardia and stimulation of the high right atrium, left atrium, and an unknown area of atrial myocardium by sinus impulse until such time that the latter could penetrate the atrioventricular node and overdrive the paroxysmal supraventricular tachycardia (Fig. 2).

Conversion of the tachycardia was succeeded by sinus rhythm in four cases (cases 3, 4, 5, and 10). One patient (case 1) showed irregular sinus cycles with

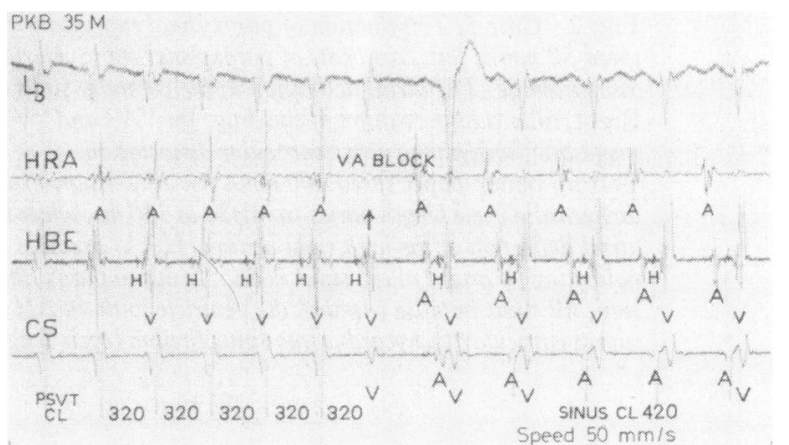

Fig. 1 Case 1. Termination of paroxysmal supraventricular tachycardia by abrupt ventriculoatrial block. The cycle length of paroxysmal supraventricular tachycardia is constant (320 ms) until the seventh complex where " $V$ " is not followed by " $A$ " (arrow). The first sinus beat shows aberrant conduction.

Abbreviations as in text.

QRS aberrancy with junctional escapes followed by a sudden change to regular sinus rhythm, and another (case 2) developed junctional escape succeeded by sinus capture and sinus rhythm.

In four patients (cases 6, 7, 8, and 9) paroxysmal supraventricular tachycardia could not be abolished despite administration of the additional dose of the 


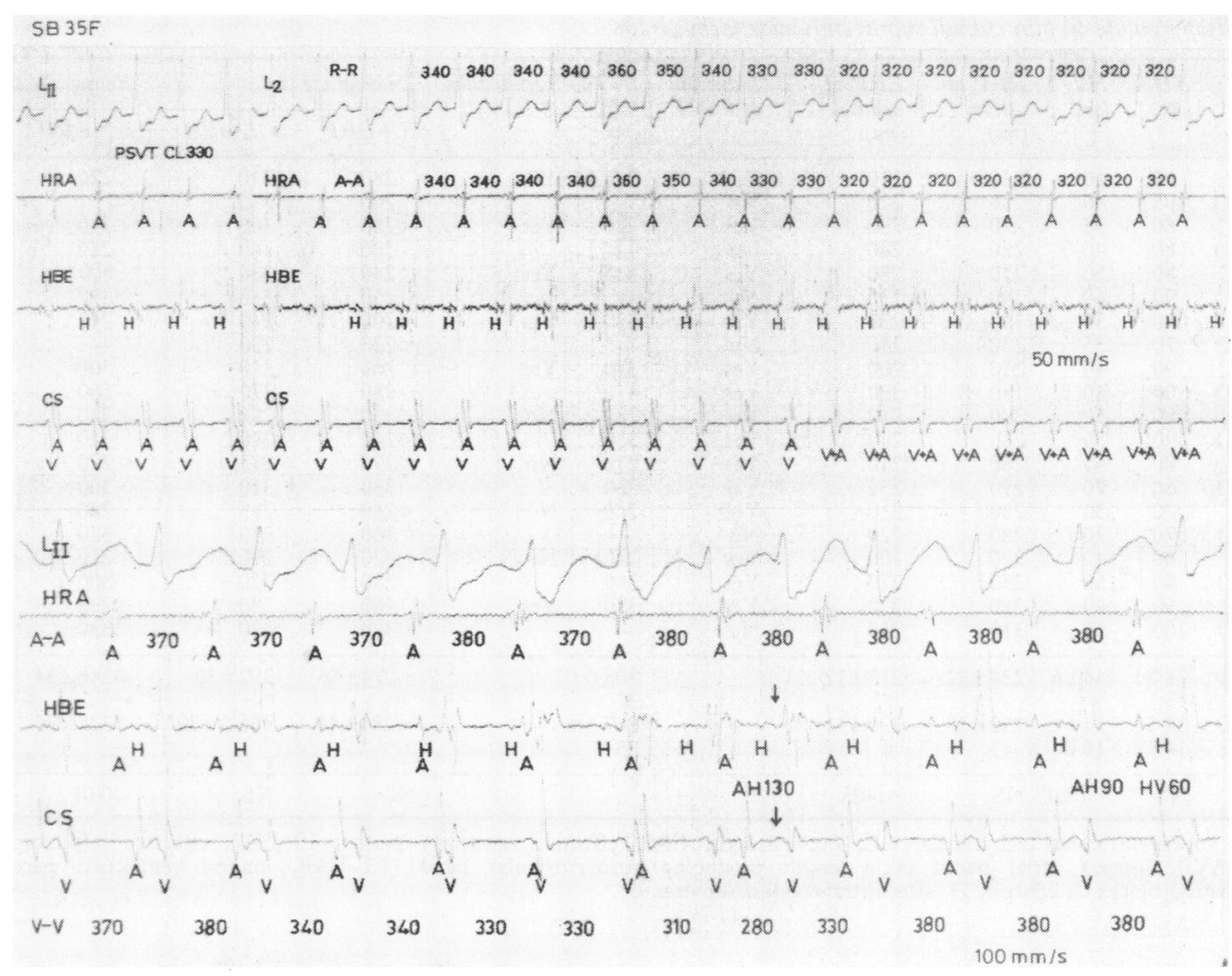

Fig. 2 Case 5. Termination of paroxysmal supraventricular tachycardia by sinus overdrive. Top panel: paper speed $50 \mathrm{~mm} / \mathrm{s}$; left, five beats of paroxysmal supraventricular tachycardia (cycle length $330 \mathrm{~ms}$ ) before disopyramide. The atrial activation in the coronary sinus electrogram immediately follows ventricular activation. Right, after administration of the drug, the " $A$ " and " $V$ " complexes gradually get superimposed on each other, suggesting isorhythmic atrioventricular dissociation.

Bottom panel: paper speed $100 \mathrm{~mm} / \mathrm{s}$ : in a later part of the continuous record the paroxysmal supraventricular tachycardia cycle length varies from 330 to $380 \mathrm{~ms}$, while the atrial cycle length is constant at 370 to $380 \mathrm{~ms}$. The atrial deflection at the high right atrium (HRA) precedes that at the His bundle electrogram and coronary sinus, indicating its origin in the sinus node. "Sinus to paroxysmal supraventricular tachycardia dissociation" is clearly seen, till sinus impulse captures the ventricle with an AH interval of $130 \mathrm{~ms}$ (arrow) converting the paroxysmal supraventricular tachycardia into sinus rhythm (cycle length $380 \mathrm{~ms}, A H 90 \mathrm{~ms}, H V 60 \mathrm{~ms}$ ).

drug. The cycle length of the tachycardia, however, increased significantly from $270 \pm 8 \mathrm{~ms}$ to $377.5 \pm 28$ $\mathrm{ms}(\mathrm{p}<0.01)$.

Cycle length during sinus rhythm immediately after termination of paroxysmal supraventricular tachycardia was $509.5 \pm 66 \mathrm{~ms}$ (range 395 to $640 \mathrm{~ms}$ ), not significantly different from the basal sinus cycle length of $578 \pm 107 \mathrm{~ms}$ (NS). The AH interval of $84.5 \pm 14 \mathrm{~ms}$ (range 60 to $105 \mathrm{~ms}$ ) after the drug was also not significantly different (NS). The HV interval was, however, significantly prolonged to $54 \cdot 5 \pm 10 \cdot 6$ ms (range $40-70 \mathrm{~ms})(\mathrm{p}<0.01)$. This increase was most pronounced in cases receiving the additional dose of the drug (Table).

\section{ANTEROGRADE CONDUCTION PROPERTIES}

The effective refractory period of the atrium was $234 \pm 32 \mathrm{~ms}$ (range 190 to $280 \mathrm{~ms}$ ) before, and $250 \pm 39$ $\mathrm{ms}$ (range 180 to $310 \mathrm{~ms}$ ) after the drug (NS). The atrial paced cycle length producing AH Wenckebach block was $292 \pm 30 \mathrm{~ms}$ (range 240 to $330 \mathrm{~ms}$ ) before, and $306.5 \pm 30 \mathrm{~ms}$ (range 250 to $340 \mathrm{~ms}$ ) after disopyramide (NS). The atrial paced cycle length producing atrioventricular block increased in seven, decreased in one (case 5), and remained unchanged in two patients (Fig. 3). The cycle length of paroxysmal supraventricular tachycardia $(308.5 \pm 37 \mathrm{~ms})$ was longer than the paced cycle length that produced atrioventricular nodal block $(292 \pm 30 \mathrm{~ms})$ during the 


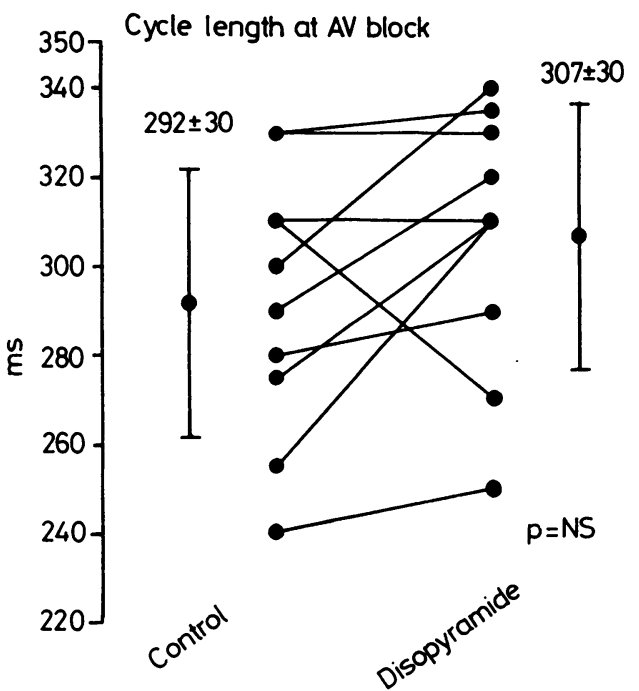

Fig. 3 Effect of disopyramide on atrial paced cycle length producing atrioventricular block.

control study.

The effective refractory period of the anterograde fast pathway was $\leqslant 274 \pm 56 \mathrm{~ms}$ (range $<200$ to 400 $\mathrm{ms}$ ) before, and $\leqslant 284 \pm 44 \mathrm{~ms}$ (range $<220$ to $360 \mathrm{~ms}$ ) after the drug (NS) (Fig. 4). The effective refractory period of the anterograde slow pathway could not be compared before and after disopyramide because atrioventricular nodal conduction was limited by atrial refractoriness before and/or after the drug.

\section{RETROGRADE CONDUCTION PROPERTIES}

Disopyramide increased the effective refractory period of the ventricle from $215 \pm 12 \mathrm{~ms}$ (range 200 to $230 \mathrm{~ms}$ ) to $229 \pm 11 \mathrm{~ms}$ (range 210 to $240 \mathrm{~ms}$ ) $(p<0.05)$. During the control study the ventricular paced cycle length that produced ventriculoatrial block ranged from $<260$ to $325 \mathrm{~ms}$ (mean $\leqslant 296.5 \pm 25$ $\mathrm{ms}$ ). After disopyramide the ventricular paced cycle length that produced ventriculoatrial block increased in all the patients irrespective of whether or not the paroxysmal supraventricular tachycardia was terminated by the drug (mean $358 \pm 60 \mathrm{~ms}$; range 286 to 470 ms) $(p<0.01)$ (Fig. 5). In two cases (1 and 4) ventricular pacing at a cycle length just shorter than the sinus cycle length disclosed complete abolition of ventriculoatrial conduction (Fig. 6). The ventriculoatrial conduction times at identical pacing rates were longer after disopyramide compared with control in all the cases. In all the subjects the cycle length of paroxysmal supraventricular tachycardia $(308.5 \pm 37 \mathrm{~ms})$ was longer than the cycle length that produced ven-
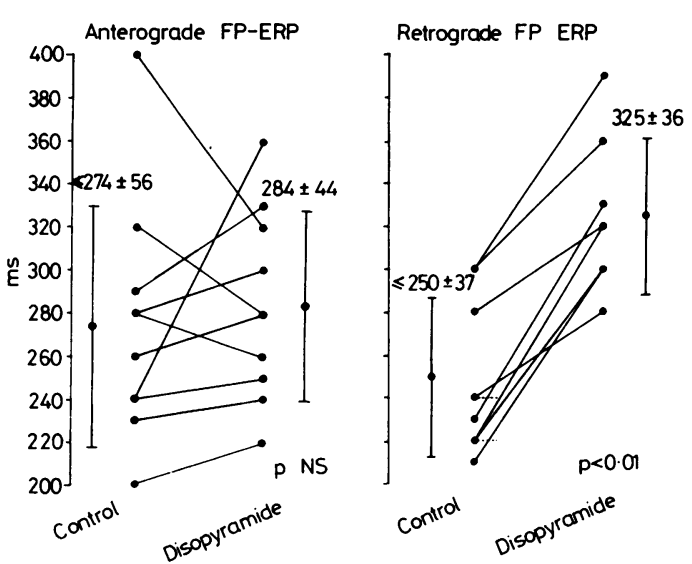

Fig. 4 Effect of disopyramide on the effective refractory period of anterograde (left panel) and retrograde (right panel) fast pathway. The horizontal interrupted lines represent two cases in which ventriculoatrial conduction was abolished by the drug.

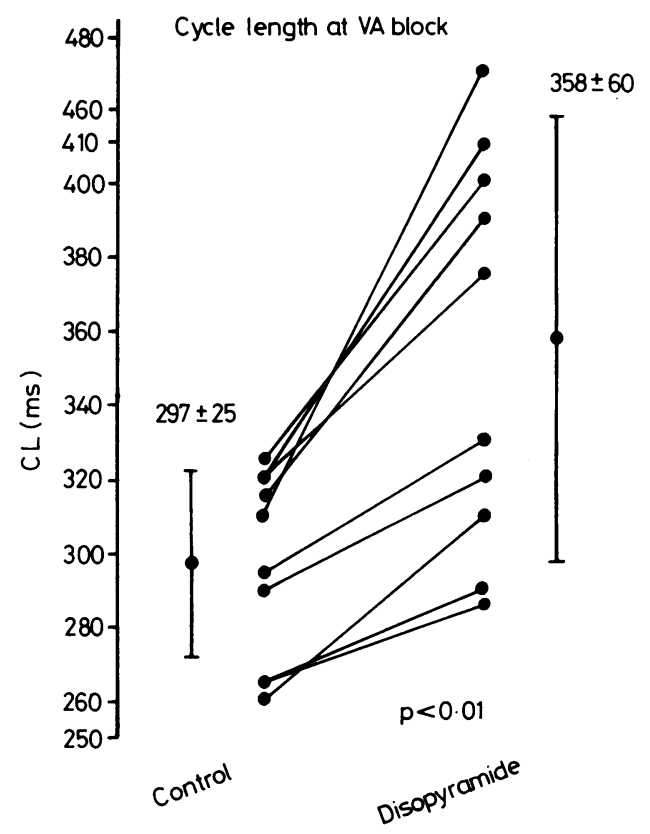

Fig.5 Effect of disopyramide on ventricular paced cycle length producing ventriculoatrial block.

triculoatrial block before disopyramide $(296.5 \pm 25$ ms).

The effective refractory period of the retrograde fast pathway before disopyramide was $\leqslant 246 \pm 34 \mathrm{~ms}$ (range $<210$ to $300 \mathrm{~ms}$ ). After disopyramide the effec- 


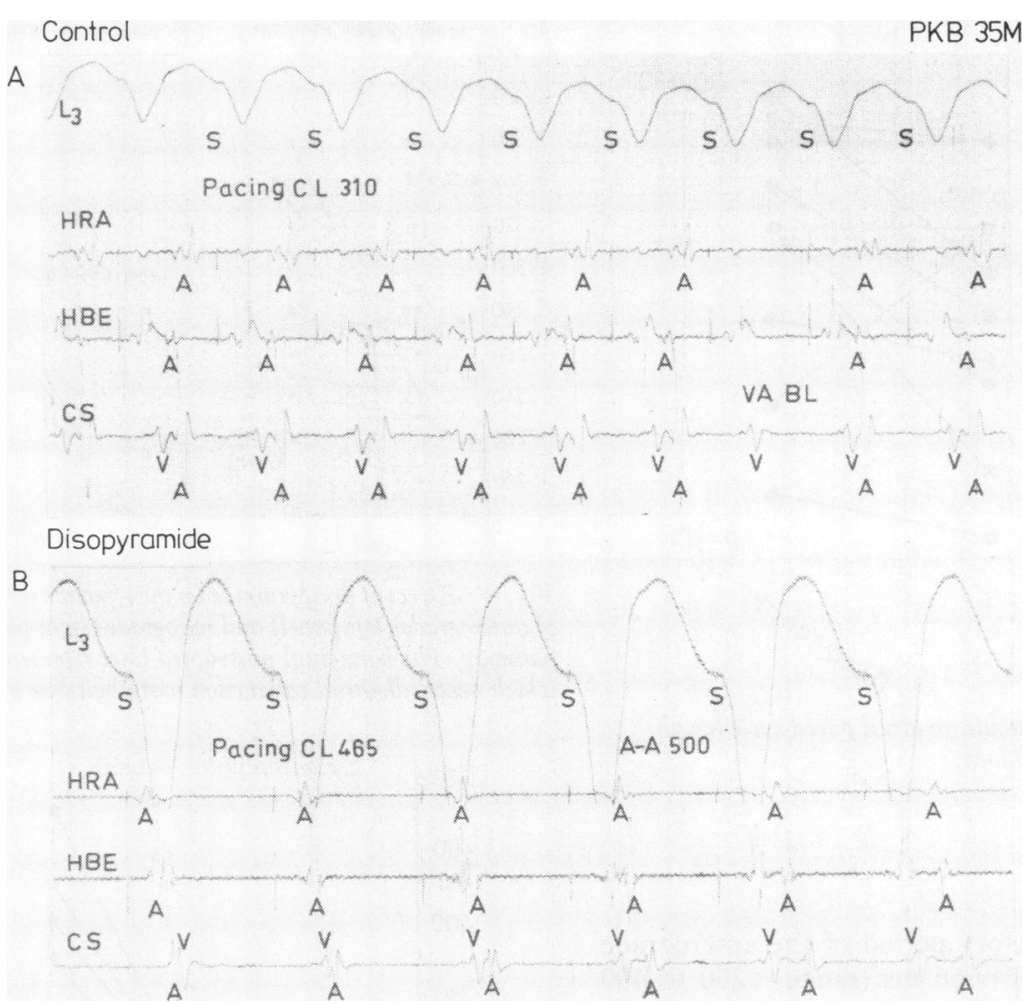

Fig. 6 Case 1. (A) Before disopyramide; ventriculoatrial block occurred at ventricular paced cycle length of $310 \mathrm{~ms}$. (B) After disopyramide; ventricular pacing at a cycle length of $465 \mathrm{~ms}$ shows ventriculoatrial dissociation. The sinus cycle length is $500 \mathrm{~ms}$ with normal sequence of atrial activation.

tive refractory period of the retrograde fast pathway could be determined in eight cases only. This was because ventriculoatrial conduction was totally abolished in two. The effective refractory period ranged from 280 to $390 \mathrm{~ms}$ (mean $325 \pm 36 \mathrm{~ms}$ ) (Fig. 4). This increase in effective refractory period was statistically significant $(p<0.01)$. Additionally, the increase in effective refractory period of the retrograde fast pathway in the eight cases in which both pre- and post-drug values of effective refractory period were available (before drug $\leqslant 250 \pm 37 \mathrm{~ms}$, range $<210$ to $300 \mathrm{~ms})$ was also significant $(\mathrm{p}<0.01)$.

\section{REINDUCTION OF PAROXYSMAL}

\section{SUPRAVENTRICULAR TACHYCARDIA}

While six subjects lost the ability to reinitiate the tachycardia, paroxysmal supraventricular tachycardia could still be induced in four (cases 5, 6, 7, and 9) after disopyramide (Fig. 7). Among the latter, three (cases 6,7, and 9) had not converted to sinus rhythm with the drug and the fourth (case 5) had responded with sinus overdrive. In these four cases the parox- ysmal supraventricular tachycardia cycle length was $290 \pm 29 \mathrm{~ms}$ (range 270 to $340 \mathrm{~ms}$ ) before and $\frac{0}{3}$ $367.5 \pm 35 \mathrm{~ms}$ (range 330 to $410 \mathrm{~ms}$ ) after disopyramide $(p<0.05)$ (Fig. 8). The ventricular paced cycle length producing ventriculoatrial block increased in all four, from a mean of $285 \pm 26 \mathrm{~ms} 5$ before to $318 \pm 41 \mathrm{~ms}$ after the drug (Fig. 9). Among the former six cases, paroxysmal supraventricular tachycardia was not inducible despite achieving $\mathrm{AH}_{\mathrm{O}}$ intervals equal to or longer than the critical $\mathrm{AH}$ time that had initiated paroxysmal supraventricular tachycardia in the control state. This finding suggests ${ }^{\omega}$ that an increase in the retrograde fast pathway refrac tory period was responsible for failure to initiat paroxysmal supraventricular tachycardia after the drug.

During the control study, the cycle length of paroxysmal supraventricular tachycardia $\left(308.5 \pm 3 \frac{{ }_{0}}{\mathrm{D}}\right.$ $\mathrm{ms}$ ) was longer than the atrial paced cycle length thaf produced AH block (292 $\pm 30 \mathrm{~ms}$ ) in all the patients? Likewise, in the four patients in whom sustained paroxysmal supraventricular tachycardia could be 


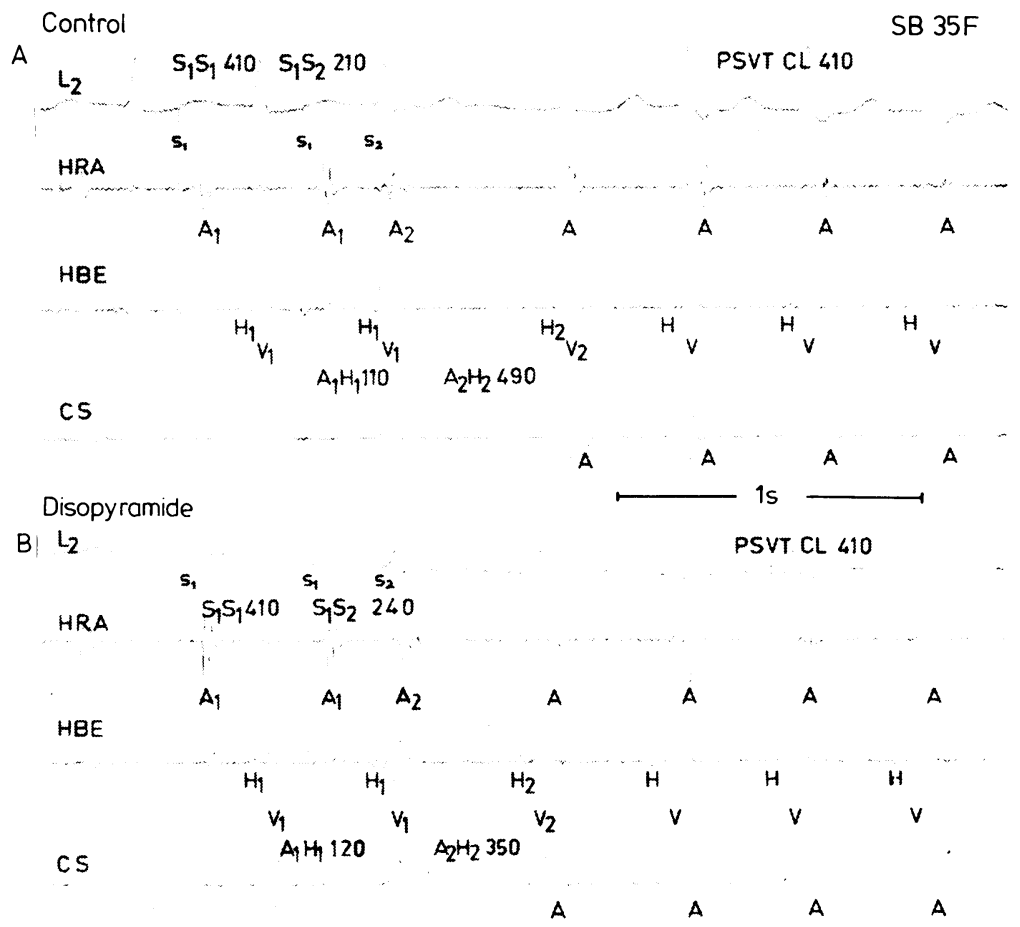

Fig. 7 Case 5. (A) Before disopyramide; induction of paroxysmal supraventricular tachycardia by single atrial extrastimulus $\left(S_{1} S_{2}=210 \mathrm{~ms}\right) . A_{2}$ is conducted to the ventricle with $\mathrm{A}_{2} \mathrm{H}_{2}$ of $490 \mathrm{~ms}$, and initiates the tachycardia. Within a few seconds the tachycardia spontaneously accelerated to a cycle length of $330 \mathrm{~ms}$ as shown in Fig. 2.

(B) After disopyramide; driving cycle length is same as in $(A)$. Single atrial extrastimulus $\left(S_{2}\right)$ delivered at a coupling interval of $240 \mathrm{~ms}$ conducts with $\mathrm{A}_{2} \mathrm{H}_{2}$ of $350 \mathrm{~ms}$ to initiate the paroxysmal supraventricular tachycardia. No acceleration of the paroxysmal supraventricular tachycardia was seen.

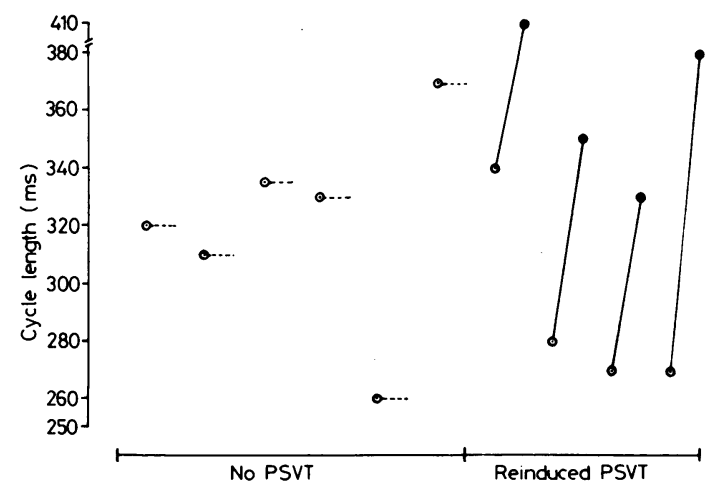

Fig. 8 Effect of disopyramide on reinduction of paroxysmal supraventricular tachycardia. Open circles represent cycle length of the tachycardia before disopyramide, and solid circles the cycle length of paroxysmal supraventricular tachycardia induced after administration of drug. Internupted lines show cases in which paroxysmal supraventricular tachycardia could not be reinduced. reinduced after disopyramide, the cycle length of paroxysmal supraventricular tachycardia $(367 \cdot 5 \pm 35$ $\mathrm{ms}$ ) was longer than the atrial paced cycle length which produced atrioventricular block (297.5 \pm 19 $\mathrm{ms})$. Three of the six patients in whom we failed to reinduce paroxysmal supraventricular tachycardia after the drug had a cycle length of paroxysmal supraventricular tachycardia before the drug longer than the atrial paced cycle length producing $\mathrm{AH}$ block after the drug. These findings are consistent with the observation that the anterograde limb was not the limiting factor in the induction or sustainment of paroxysmal supraventricular tachycardia after disopyramide.

In all patients, the cycle length of paroxysmal supraventricular tachycardia $(308.5 \pm 37 \mathrm{~ms})$ was longer than the ventricular paced cycle length producing ventriculoatrial block $(\leqslant 296.5 \pm 25 \mathrm{~ms})$ before disopyramide. In those six patients in whom paroxysmal supraventricular tachycardia could not be induced 


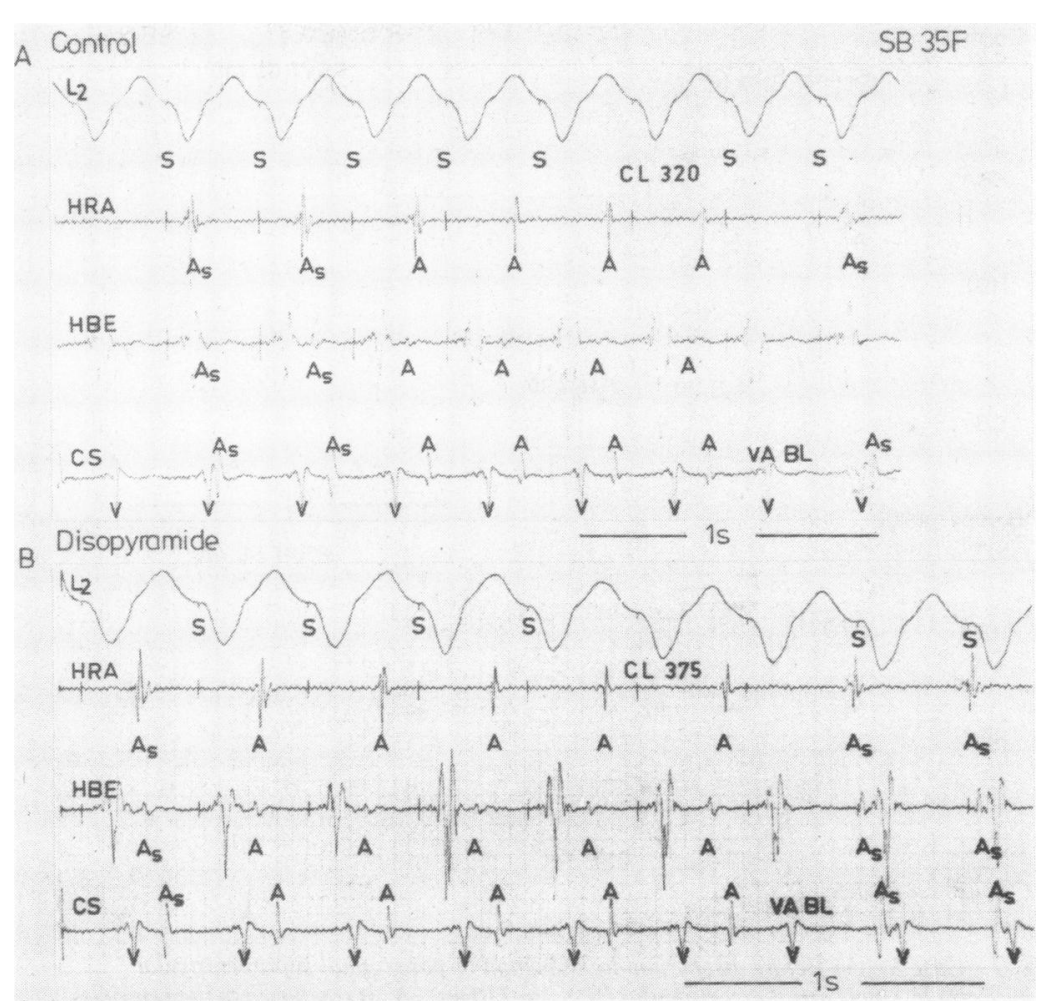

Fig. 9 Case 5. Same patient as in Fig. 2 and 7. While producing facilitation of anterograde conduction disopyramide depressed the retrograde conduction. The ventricular paced cycle length producing ventriculoatrial block increased from $320 \mathrm{~ms}(A)$ to $375 \mathrm{~ms}$ (B). Magnitude of depression, however, was insufficient to prevent reinduction of paroxysmal supraventricular tachycardia. A, retrograde atrial activation by ventricular paced impulse; As, atrial activation by sinus impulse.

after the drug the ventricular paced cycle length that produced ventriculoatrial block after disopyramide $(385 \pm 53 \mathrm{~ms})$ was longer than the cycle length of paroxysmal supraventricular tachycardia (321 \pm 33 ms) during control study. In the other four patients with inducible paroxysmal supraventricular tachycardia after the drug the cycle lengths producing ventriculoatrial block ( $318 \pm 41 \mathrm{~ms}$ ) and effective refractory period of the retrograde fast pathway $(320 \pm 28$ $\mathrm{ms}$ ) were shorter than the post-drug cycle lengths of paroxysmal supraventricular tachycardia $(367.5 \pm 35$ $\mathrm{ms}$ ), indicating that the fast pathway was not sufficiently inhibited to prevent perpetuation of paroxysmal supraventricular tachycardia.

\section{Discussion}

The initiation and sustainment of re-entrant tachycardia require the presence of a closed electrical circuit, a unidirectional block in one of the limbs, (usually manifest as a discrepancy in anterograde refractory periods of the two limbs), and a slow vel-ô ocity of conduction in a part of the circuit. In patients with paroxysmal supraventricular tachycardia causedo by atrioventricular nodal re-entry (longitudinal dissociation of atrioventricular node), the re-entrant cir-o cuit consists of a slow anterograde pathway and a retrograde fast (atrioventricular nodal) pathway alongo with a proximal and a distal common pathway (within 0 the atrioventricular node) which conduct the re-N entrant impulses. ${ }^{23} 24$ Drugs that change the refrac-O toriness or conduction velocity of a component of the re-entrant circuit have been shown to disturb this finely adjusted echo zone and terminate the tachycar-on dia. Such drugs have also proved useful in preventing recurrences of tachycardia during follow-up..$^{37825}$

While some reports ${ }^{13-16}$ of the beneficial effects of intravenous disopyramide in terminating acute ${ }_{0}$ attacks of paroxysmal supraventricular tachycardiahave been published, the mechanism of termination 
and overall efficacy of the drug in relation to conventional and other newer antiarrhythmic drugs in a select group of patients mediating the tachycardia via dual atrioventricular nodal pathways have not so far been studied in detail. Disopyramide could convert $60 \%$ of such attacks of paroxysmal supraventricular tachycardia into normal sinus rhythm in our study material. Swiryn et al.26 reported that oral disopyramide could prevent induction of sustained paroxysmal supraventricular tachycardia in six out of nine cases $(67 \%)$ of atrioventricular nodal re-entrance. Intravenous verapamil converts 80 to $100 \%$ of episodes of paroxysmal supraventricular tachycardia into sinus rhythm but is much less effective in preventing recurrences when administered orally 32728 because of considerable first pass hepatic metabolism. Other drugs that have been shown to be effective in preventing induction of atrioventricular nodal reentrant paroxysmal supraventricular tachycardia include (percentages in parentheses): intravenous ouabain (44 to $54 \%),{ }^{4}$ intravenous propranolol (41 to $44 \%),{ }^{7}$ intravenous ouabain plus propranolol $(58 \%),{ }^{7}$ intravenous procainamide $(65 \%),{ }^{6}$ and oral quinidine $(78 \%) .{ }^{78}$ It appears from this review of published reports that, though somewhat less effective than verapamil in converting acute attacks, intravenous disopyramide compares favourably with other drugs in controlling paroxysmal supraventricular tachycardia mediated by dual atrioventricular nodal pathways and may possess the additional advantage of effectively preventing recurrences on chronic oral treatment. ${ }^{26}$ We have not attempted specifically to test in our study whether chronic oral administration of disopyramide prevents recurrence of paroxysmal supraventricular tachycardia, but such proof in a large number of patients with dissociation of the atrioventricular node into dual pathways and paroxysmal supraventricular tachycardia is desirable.

As observed in our study, Befeler et al..$^{29}$ have also reported no change or shortening of the atrial effective and functional refractory periods after intravenous administration of disopyramide. On the other hand, other investigators 103031 found increases in these variables. An increase in ventricular effective refractory period has also been shown, ${ }^{10}$ but anterograde atrioventricular conduction has been shown to be depressed, unaffected, or even facilitated by the drug. 10293032 Both anterograde slow pathway conduction (atrial paced cycle length producing atrioventricular block) and effective refractory period of anterograde fast pathway were not significantly affected in the present study.

In sharp contrast to its effect on the anterograde conduction through the atrioventricular node, disopyramide selectively and uniformly depressed conduction through the retrograde fast pathway in all the patients, as shown by the lowering of ventricular paced rate producing ventriculoatrial block, and an increase in the effective refractory period of the retrograde fast pathway. This effect was responsible for termination of paroxysmal supraventricular tachycardia in five patients (ventriculoatrial block) and prevention of reinduction of paroxysmal supraventricular tachycardia in six cases as shown by failure to induce atrioventricular nodal re-entrant echo despite achievement of an $\mathrm{AH}$ interval equivalent to or longer than the one that precipitated paroxysmal supraventricular tachycardia in the control state. It is clear from our data that the fast pathway, while unaffected in the anterograde direction, was rendered incapable of conducting retrogradely. Though the nature of this retrograde pathway is subject to some discussion, the available evidence indicates that it is located intranodally and is identical to the anterograde fast pathway. ${ }^{33}$

The results of other studies on the effect of oral quinidine,${ }^{78}$ and oral disopyramide ${ }^{26}$ on induction of atrioventricular nodal re-entrant tachycardia corroborate the data obtained by us on intravenous disopyramide on electrophysiologically confirmed dissociation of atrioventricular nodal pathways mediated paroxysmal supraventricular tachycardia. In our study disopyramide did marginally depress the anterograde slow pathway conduction in some patients but this did not appear to be a limiting factor in inducing or sustaining the tachycardia. This is in contradistinction to the actions of intravenous verapamil, ${ }^{32728}$ digitalis, ${ }^{47}$ and propranolol ${ }^{5}$ which, by and large, increase the anterograde slow pathway refractoriness and only occasionally depress the retrograde fast pathway conduction. Intravenous procainamide prevents induction of paroxysmal supraventricular tachycardia in some patients ${ }^{6}$ by inhibiting the retrograde fast pathway but may have the disadvantage of decreasing the anterograde slow pathway refractoriness (vagolytic effect) in some patients. Atrioventricular conduction was facilitated by intravenous disopyramide in one of our patients (case 5) who overdrove the paroxysmal supraventricular tachycardia by sinus tachycardia. Alterations in the sinus rate after disopyramide therapy are variable and related to a complex interaction between the direct depressant action on sinus node automaticity, ${ }^{32}$ its anticholinergic effects, ${ }^{34}$ and reflex baroreceptor mediated sympathomimetic effect caused by peripheral vasodilatation. Anterograde conduction was significantly depressed by oral disopyramide in the study of Swiryn et al. ${ }^{26}$ The discrepancy between their data and our results could possibly be the result of more prominent anticholinergic effects of the drug after intravenous administration.

Whenever disopyramide failed to terminate parox- 
ysmal supraventricular tachycardia, it produced a reduction in tachycardia rate. In those four patients in whom paroxysmal supraventricular tachycardia was still inducible after disopyramide, the depression in retrograde conduction was insufficient to prevent continuation of the tachycardia. Anterograde conduction was depressed in three and facilitated in one of these cases. The cycle length of the reinduced paroxysmal supraventricular tachycardia was, however, significantly increased in all the patients.

Our data indicate that intravenous disopyramide depresses retrograde fast pathway conduction and thus terminates, or prevents induction of, paroxysmal supraventricular tachycardia in patients with atrioventricular nodal re-entrant tachycardia. Care needs to be exercised in prescribing the drug routinely in all non-specific supraventricular tachycardias because of the possibility of an increase in ventricular rate by development of 1:1 conduction through the atrioventricular node in cases of atrial flutter or paroxysmal supraventricular tachycardia caused by an ectopic atrial focus or intra-atrial re-entry in the absence of concomitant administration of atrioventricular nodal depressants (digoxin, beta blockers). This risk of $1: 1$ conduction on the development of atrial flutter in patients receiving disopyramide for long term prophylaxis against paroxysmal supraventricular tachycardia can be assessed during intracardiac electrophysiological study. It could not be assessed in the absence of such a test were the drug to be given empirically to all patients with intranodal paroxysmal supraventricular tachycardia because the infra-Hisian delay induced by the drug may or may not protect the ventricles from rapid response.

\section{References}

1 Josephson ME, Kastor JA. Supraventricular tachycardia: mechanisms and management. Ann Intern Med 1977; 87: 346-58.

2 Wu D, Denes P, Amat-Y-Leon F, et al. Clinical, electrocardiographic and electrophysiologic observations in patients with paroxysmal supraventricular tachycardia. Am $\mathcal{F}$ Cardiol 1978; 41: 1045-51.

3 Wellens HJJ, Tan SL, Bär FWH, Düren DR, Lie KI, Dohmen HM. Effect of verapamil studied by programmed electrical stimulation of the heart in patients with paroxysmal re-entrant supraventricular tachycardia. $\mathrm{Br}$ Heart F 1977; 39: 1058-66.

4 Wellens HJJ, Düren DR, Liem KL, Lie KI. Effect of digitalis in patients with paroxysmal atrioventricular nodal tachycardia. Circulation 1975; 52: 779-88.

5 Wu D, Denes P, Dhingra RC, Khan A, Rosen KM. The effects of propranolol on induction of A-V nodal reentrant paroxysmal tachycardia. Circulation 1974; 50: 665-77.

6 Wu D, Denes P, Bauernfeind R, Kehoe R, Amat-YLeon F, Rosen KM. Effects of procainamide on atrioventricular nodal re-entrant paroxysmal tachycardia. Circulation 1978; 57: 1171-9.

7 Bauernfeind R, Wyndham CR, Dhingra RC, et al. Serial electrophysiologic testing of multiple drugs in patients with atrioventricular nodal re-entrant paroxysmal tachycardia. Circulation 1980; 62: 1341-9.

$8 \mathrm{Wu} \mathrm{D}$, Hung J, Kuo C, Hsu K, Shieh W. Effects of quinidine on atrioventricular nodal re-entrant paroxysmal tachycardia. Circulation 1981; 64: 823-31.

9 Mokler CM, Van Arman CG. Pharmacology of a new anti-arrhythmic agent, 4-diisopropyl-amino-alphaphenyl-alpha-(2 pyridyl)-butyramide (SC-7031). $f$ Pharmacol Exp Ther 1962; 136: 114-24.

10 Spurrell RAJ, Thorburn CW, Camm J, Sowton E, Deuchar DC. Effects of disopyramide on electrophysiological properties of the specialized conduction system in man and the accessory atrioventricular pathway in Wolff-Parkinson-White syndrome. Br Hear $\mathcal{f}$ 1975; 37: 861-7.

11 Singh BN, Collett JT, Chew CYC. New perspectives in the pharmacologic therapy of cardiac arrhythmias. Prog Cardiovasc Dis 1980; 22: 243-301.

12 Bennett DH. Disopyramide in patients with the WolffParkinson-White syndrome and atrial fibrillation. Chest 1978; 74: 624-8.

13 Mizgala HF, Huvelle PR. Acute termination of cardiac arrhythmias by intravenous disopyramide. $f$ Int Med Res 1976; 4 (suppl I): 82-5.

14 Deano DA, Wu D, Mautner RK, Sherman RH, Ehsani $\mathrm{AE}$, Rosen KM. The antiarrhythmic efficacy of intravenous therapy with disopyramide phosphate. Chest 1977; 71: 597-606.

15 Luoma PV, Kujala PA, Juustila H, Takkunen JT. Efficacy of intravenous disopyramide in the termination of supraventricular arrhythmias. $\mathcal{F}$ Clin Pharmacol 1978; 18: 293-301.

16 Luoma PV, Aitio ML, Kujala PA, Takkunen JT. Intravenous disopyramide: serum levels and efficacy in supraventricular arrhythmia. Current Therapeutic Research 1980; 27: 839-43.

17 Josephson ME, Seides SF. Clinical cardiac electrophysiology: techniques and interpretations. Philadelphia: Lea and Febiger, 1979: 163.

18 Wu D, Denes P, Wyndham C, Amat-Y-Leon F, Dhingra RC, Rosen KM. Demonstration of dual atrioventricular nodal pathways utilizing a ventricular extrastimulus in patients with atrioventricular nodal re-entrant paroxysmal supraventricular tachycardia. Circulation 1975; 52: 789-98.

19 Goldreyer BN, Damato AN. The essential role of $N$ atrioventricular conduction delay in the initiation of N paroxysmal supraventricular tachycardia. Circulation 1971; 43: 679-87.

20 Wellens HJJ, Durrer D. The role of an accessory atrioventricular pathway in reciprocating tachycardia: observations in patients with and without the WolffParkinson-White syndrome. Circulation 1975; 52: 58-72.

21 Denes P, Wu D, Dhingra RC, Chiquimia R, Rosen KM. Demonstration of dual A-V nodal pathways in patients with paroxysmal supraventricular tachycardia. Circula-

22 Amat-Y-Leon F, Dhingra RC, Wu D, Denes P, 
Wyndham C, Rosen KM. Catheter mapping of retrograde atrial activation. Observations during ventricular pacing and A-V nodal re-entrant paroxysmal tachycardia. Br Heart $\mathcal{F}$ 1976; 38: 355-62.

23 Josephson ME, Kastor JA. Paroxysmal supraventricular tachycardia. Is the atrium a necessary link? Circulation 1976; 54: 430-5.

24 Bauernfeind RA, Wu D, Denes P, Rosen KM. Retrograde block during dual pathway atrioventricular nodal re-entrant paroxysmal tachycardia. Am $\mathcal{F}$ Cardiol 1978; 42: 499-505.

25 Wu D, Amat-Y-Leon F, Simpson RJ Jr, et al. Electrophysiological studies with multiple drugs in patients with atrioventricular re-entrant tachycardias utilizing an extranodal pathway. Circulation 1977; 56: 727-36.

26 Swiryn S, Bauernfeind RA, Wyndham CRC, et al. Effects of oral disopyramide phosphate on induction of paroxysmal supraventricular tachycardia. Circulation 1981; 64: 169-75.

27 Schamroth L, Krikler DM, Garrett C. Immediate effects of intravenous verapamil in cardiac arrhythmias. $\mathrm{Br} \mathrm{Med}$ f 1972; i: 660-2.

28 Krikler DM, Spurrell RAJ. Verapamil in the treatment of paroxysmal supraventricular tachycardia. Postgrad Med F 1974; 50: 447-53.

29 Befeler B, Castellanos A Jr, Wells DE, Vagueiro MC,
Yeh BK. Electrophysiologic effects of the antiarrhythmic agent disopyramide phosphate. Am f Cardiol 1975; 35: 282-7.

30 Josephson ME, Caracta AR, Lau SH, Gallagher JJ, Damato AN. Electrophysiological evaluation of disopyramide in man. Am Heart $\mathcal{F} 1973$; 86: 771-80.

31 Caracta AR. The electrophysiology of Norpace. Part III. Angiology 1975; 26: 120-3.

32 Birkhead JS, Williams EMV. Dual effect of disopyramide on atrial and atrioventricular conduction and refractory periods. $\mathrm{Br}$ Heart $\mathcal{f}$ 1977; 39: 657-60.

33 Rosen KM, Bauernfeind RA, Wyndham CR, Dhingra RC. Retrograde properties of the fast pathway in patients with paroxysmal atrioventricular nodal re-entrant tachycardia. Am f Cardiol 1979; 43: 863-5.

34 Marrot PK, Ruttley MST, Winterbottam JT, et al. A study of the acute electrophysiological and cardiovascular action of disopyramide in man. Eur $\mathcal{f}$ Cardiol 1976; 4: 303-12.

Requests for reprints to Dr Kamal K Sethi, Department of Cardiology, GB Pant Hospital, New Delhi110002 , India. 